\title{
Insights into the effect of structure-directing agents on structural properties of mesoporous carbon for polymer electrolyte fuel cells
}

\author{
A ARUNCHANDER, K G NISHANTH, K K TINTULA, S GOUSE PEERA and A K SAHU* \\ CSIR - Central Electrochemical Research Institute - Madras Unit, CSIR Madras Complex, Chennai 600 113, India
}

MS received 6 August 2014; revised 27 August 2014

\begin{abstract}
Synthesis of mesoporous carbon (MC) with well-defined morphologies and, wide range of surface area and pore size, is reported by organic-organic interaction between thermally decomposable surfactants (structuredirecting agents) and the cost-effective carbon precursors, such as phloroglucinol and formaldehyde. Selected surfactants based on tri-block co-polymer, non-ionic and ionic, are used for synthesis of MCs with wide variation in their physical properties. The present method could be applied to large-scale production of porous carbon with desired surface area and pore morphology and would practically be relevant to many emerging technologies including electrochemical power sources such as super-capacitors and fuel cells. In the present study, we have successfully used MCs as gas-diffusion layers in fuel cell electrodes and established proper balance between air permeability and water management. The porous carbon contributes significantly to reduce mass transfer existing at high current density region resulting in improved performance of the polymer electrolyte fuel cells.
\end{abstract}

Keywords. Mesoporous carbon; gas-diffusion layer; air permeability; fuel cell.

\section{Introduction}

In recent years, although ground-breaking progress has been made for polymer electrolyte fuel cells (PEFCs) in terms of membranes, anode/cathode catalysts, bipolar-plate materials as well as the system design; a key performance limitation called the mass transport loss that originates from gas-diffusion layer (GDL) remains a major challenge. Proper water management is therefore required to avoid cathode flooding by removing excess liquid water generated at the cathode and for easy access of reactant gases to the active catalyst layer. ${ }^{1}$ The GDL typically has a dual-layer structure, ${ }^{2}$ the first layer is a fibrous carbon paper or carbon cloth, which serves as a current collector and a physical support for the electrode. The second layer is a thinner microporous layer consisting of carbon black powder, which helps promoting reactants to the active catalyst layer and subsequent removal of product water enhancing the PEFC performance. ${ }^{2-6}$ Overall, GDL plays an important role in water management of a PEFC, which dictates a delicate balance between membrane hydration and water removal from the electrodes. ${ }^{7-9}$ In addition to various aforesaid physical parameters of the GDL, pore structure and pore size distribution are seminal for gas permeability and determine the limiting load currentdensity of the PEFCs, especially when air is used as an oxidant. $^{2}$ Extensive work on GDL has been performed to

*Author for correspondence (akhilakumar2008@gmail.com) investigate the effect of carbon powder, such as Vulcan XC-72R, pearl black, acetylene black and Ketjen black on PEFC performance. ${ }^{10-12}$ However, microporous nature of aforementioned carbon restricts the optimal distribution of reactant at the GDL interface. Besides high surface area, distribution of micropores (pore size $<2 \mathrm{~nm}$ ) and mesopores (pore size 2-50 nm) in carbon is central for optimal distribution of reactant gas and liquid water at the solid-liquid-gas interface of PEFCs.

To address this issue, efforts have been expended to develop new carbon nano-materials with higher surface area and/or higher electrical conductivity than activated carbon and their feasibility for fuel cell electrodes. Graphitic carbon frameworks include carbon nanotubes, carbon nanofibres, carbon nanohorns, carbon nanocages and graphitic porous carbon, which have been the subject of continuing research and development. ${ }^{13-17}$ However, harsh synthesis conditions and low production yields limit large-scale and cost-effective production of these materials. Ordered mesoporous materials have received enormous attention owing to their high surface area, regular frameworks, tunable pore size with narrow pore size distribution, all of which lead to multiple potential applications. ${ }^{18-20}$ Mesoporous carbon (MC), one of the most promising materials, possesses remarkable functional properties and excellent chemical/thermal stability, which make it suitable for applications in catalysis, ${ }^{21,22}$ adsorbents, ${ }^{23}$ sensors, ${ }^{24}$ electrode materials ${ }^{25-27}$ and energy storage. ${ }^{28,29}$ MC materials, comprising regular arrays of uniform mesopores are highly attractive from the viewpoint of pore 
structure and pore sizes that provide improved mass transport, electron transport and easy removal of product water from the PEFCs. ${ }^{30-32}$ Ordered mesoporous carbon (OMC) materials can be prepared from hard template methods that include: (i) forming a composite by filling the nano-channels of hard template (usually SBA-15, MCM-48 and colloidal silica) with appropriate carbon precursors, (ii) carbonization of the composite at high temperature and (iii) removal of templates with aqueous $\mathrm{NaOH}$ or $\mathrm{HF}^{33-42}$ Accordingly, the resultant porous carbon happens to be the structural replica of the hard template used. ${ }^{43-47}$ In this process, an additional step is mandatory to prepare silica hard templates prior to the multi-step template synthesis, making it a long and complicated process. ${ }^{21}$ As an alternative, many researchers have focused on synthesis of MC materials in direct onestep method without the hard template route ${ }^{48,49}$ that can eliminate the preformed template and tedious infiltration steps. Although, these classes of MCs show some irregularly interconnected pores and relatively wider pore size distribution, their synthesis is simple and mesoporous structures can be controlled by varying the molar ratio of the respective precursors. ${ }^{50,56}$ Amphiphilic PEO-PPO-PEO triblock copolymers, which are commercially available as Pluronics or Synperonics, have proven to be versatile and efficient structure-directing agents for the fabrication of OMC..$^{57,58}$ Since the reactant distribution and proper water management in PEFC strongly depend on the porous structure of carbon materials in a GDL layer, it is of interest to learn this behaviour as a function of pore structure. The nature and kind of structure-directing agent play a crucial role in tuning the geometry of the pore structure while preparing the MCs.

Here, we report the synthesis of uniform porous carbon with interesting morphological variation by organic-organic interaction between a thermosetting polymer with varying thermally decomposable surfactants (structure-directing agents) and a mixture of phloroglucinol and formaldehyde as a cost-effective carbon precursor. The MCs were surface functionalized with conducting polymer, such as poly(3,4ethylenedioxythiophene) (PEDOT). The strategy of making composites of MC and PEDOT is to reduce the high hydrophobic nature of the MC owing to the presence of heteroatom in PEDOT which helps in enhancing the humidity/ hydrophilicity. The resultant high surface area MC-PEDOT composites with varying pore structures used as GDLs regulates proper reactant distribution and water management in PEFCs. 'Reactant permeability' with varying pore morphology of electrodes are contrasted with 'water release behaviour' from an operating fuel cell; the former helps investigating localized environments and is sensitive to pore morphology (shape and structures), while the latter provides insight into the water release/flux through the GDL that enables oxygen diffusion to the active catalyst sites enhancing the limiting current during fuel cell operation. This contrast provides a bridge between the fundamental understanding of the morphological structure of $\mathrm{MC}$, and the impact of these factors on reactant transport and product water removal in PEFCs.

\section{Experimental}

\subsection{Materials}

Phloroglucinol dihydrate (99\%, Acros Organics), Pluronic F-68 (PF-68, Aldrich), Brij-35, Tween-60, Triton X-100, Sodium dodecylsulphate (SDS), Hexadecyl trimethylammonium bromide (HTAB), formaldehyde (37-41\%) and absolute ethanol, all are obtained from Merck, Germany. Vulcan XC-72R carbon was obtained from Cabot Corporation. All the chemicals were used as-received. De-ionized water $(18.4 \mathrm{M} \Omega \mathrm{cm})$ used for experiments was produced by a Millipore system.

\subsection{Synthesis of MC-PEDOT composites}

MC with varying pore structure was synthesized adopting a soft-template route similar to the process described elsewhere. ${ }^{58}$ Selected structure directing agents classified into four different categories namely, tri-block co-polymers, non-ionic, anionic and cationic were considered for the synthesis of MC. The corresponding molecular formulas with other physical parameters of various structure directing agents are provided in table 1 . In brief, $1.25 \mathrm{~g}$ of each structure directing agents was mixed separately with $1.25 \mathrm{~g}$ of phloroglucinol and the mixture was dissolved in $9 \mathrm{~g}$ of 10:9 weight ratio of ethanol and water mixture under magnetic stirring at room temperature. Subsequently, $0.1 \mathrm{~g}$ of $\mathrm{HCl}$ was added to each solution as a catalyst. The admixtures were stirred at room temperature for additional $30 \mathrm{~min}$ till a light pink colour appeared. Following this, $1.3 \mathrm{~g}$ of formaldehyde was added to each of the above admixtures. All sample solutions turned cloudy after $30 \mathrm{~min}$ and separated into two layers after $1 \mathrm{~h}$. The upper layer mainly consisted of a mixture of water and ethanol, while the lower layer was a clear polymer-rich solution. The polymer solution was kept on continued stirring overnight to form an elastic but non-sticky monolith which was further cured at $100^{\circ} \mathrm{C}$ overnight. The materials were then carbonized in a tubular furnace under nitrogen atmosphere by heating ramp of $1^{\circ} \mathrm{C} \mathrm{min}-1$ from 100 to $400^{\circ} \mathrm{C}, 5^{\circ} \mathrm{C} \mathrm{min}{ }^{-1}$ from 400 to $850^{\circ} \mathrm{C}$ and then kept at $850^{\circ} \mathrm{C}$ for $2 \mathrm{~h}$. The samples were allowed to cool to room temperature. The materials were collected and ground to fine powder. Chemical polymerization of (3,4-ethylenedioxythiophene) (EDOT) on the surface of MC leads to MC-PEDOT composite wherein ammonium persulfate was used as an oxidant in an aqueous and acidic methanol solution maintained at $0-5^{\circ} \mathrm{C} .{ }^{59,60}$ The loading of PEDOT on all the MC samples prepared were kept at $20 \mathrm{wt} \%$. The product was filtered and washed copiously with de-ionized water and methanol. The resulting MC-PEDOT composites were dried under vacuum at $80^{\circ} \mathrm{C}$ for $12 \mathrm{~h}$.

\subsection{Physicochemical characterization}

Powder X-ray diffraction (XRD) patterns for MCs were obtained on a Philips Pan Analytical X-ray diffractometer 
Table 1. Physical properties of MC derived from various structure-directing agents.

\begin{tabular}{|c|c|c|c|c|c|}
\hline Category & $\begin{array}{l}\text { Structure-directing agents } \\
\text { used for synthesis of MC }\end{array}$ & $\begin{array}{l}\text { Molecular formulae and structure } \\
\text { of structure-directing agent }\end{array}$ & $\begin{array}{l}\text { Surface area } \\
\left(\mathrm{m}^{2} \mathrm{~g}^{-1}\right)\end{array}$ & $\begin{array}{c}\text { Average } \\
\text { pore size }(\mathrm{nm})\end{array}$ & $\begin{array}{l}\text { Average permeability } \\
\text { (Darcy) }\end{array}$ \\
\hline \multirow[t]{2}{*}{ Triblock co-polymer } & & $\mathrm{EO}_{75} \mathrm{PO}_{30} \mathrm{EO}_{75}$ & & & \\
\hline & PF-68 & & 468 & 4.4 & 1.26 \\
\hline \multirow[t]{6}{*}{ Nonionic } & & $\mathrm{C}_{58} \mathrm{H}_{118} \mathrm{O}_{24}$ & & & \\
\hline & Brij-35 & & 402 & 3.9 & 0.63 \\
\hline & & $\mathrm{C}_{24} \mathrm{H}_{46} \mathrm{O}_{6}\left(\mathrm{C}_{2} \mathrm{H}_{4} \mathrm{O}\right)_{n}$ & & & \\
\hline & Tween-60 & & 42 & 4.68 & 1.25 \\
\hline & & $\mathrm{C}_{14} \mathrm{H}_{22} \mathrm{O}\left(\mathrm{C}_{2} \mathrm{H}_{4} \mathrm{O}\right)_{n}(n=9-10)$ & & & \\
\hline & Triton X-100 & & 383 & 2.20 & 2.12 \\
\hline \multirow[t]{2}{*}{ Anionic } & & $\mathrm{NaC}_{12} \mathrm{H}_{25} \mathrm{SO}_{4}$ & & & \\
\hline & SDS & & 307 & 4 & 1.59 \\
\hline \multirow[t]{2}{*}{ Cationic } & & $\mathrm{C}_{16} \mathrm{H}_{33}\left(\mathrm{CH}_{3}\right)_{3} \mathrm{NBr}$ & & & \\
\hline & HTAB & & 106 & 9 & 0.82 \\
\hline
\end{tabular}

employing $\mathrm{CuK}_{\alpha}$ radiation of wavelength $1.54 \AA$. Textural and surface properties of various MCs were characterized by $\mathrm{N}_{2}$-physisorption and temperature programmed desorption, respectively. Nitrogen adsorption-desorption isotherms were measured at $77 \mathrm{~K}$ using a Micromeritics ASAP 2020. Total surface area and pore volumes were determined using the Brunauer-Emmett-Teller (BET) equation and the singlepoint method, respectively. Pore size distribution (PSD) curves were obtained by the Barrett-Joyner-Halenda method and the position of the maximum of the PSD was used as the average pore diameter. Transmission electron microscope (TEM) images for determination of pore size, pore structure and their distribution were obtained using a $200 \mathrm{kV}$ Tecnai-20 G2. For these measurements, the samples were suspended in acetone with ultrasonic dispersion for $3 \mathrm{~min}$. Subsequently, a drop of this suspension was deposited on a holey carbon grid and allowed for drying. TEM images of the samples were recorded both in the axial direction of the pores as also in the perpendicular direction. Images were recorded with a Multiscan CCD camera (model 794, Gatan) using lowdose conditions. Surface morphology of the MCs coated over macroporous substrates referred as GDLs was observed with the help a JEOL JSM 5400 SEM. Air permeabilities of GDLs comprising Vulcan $\mathrm{XC}-72 \mathrm{R}$ and all MCs were also measured with Automated Capillary Flow Porometer CFP-1500AEXBB, Porous Materials Inc., US. The working diameter $(1.5 \mathrm{~cm})$ and the thickness $(0.4 \mathrm{~mm})$ were kept identical for all samples. The tests were performed with differential airpressure applied to the samples and the corresponding air flow rates through the porous GDLs were recorded.

\subsection{Performance evaluation of PEFCs}

Performance of the PEFCs comprising MC-PEDOT composites as GDLs were examined both in $\mathrm{H}_{2} / \mathrm{O}_{2}$ and $\mathrm{H}_{2}$ /air modes and the results were compared with the PEFC comprising Vulcan XC-72R. For making membrane electrode assemblies (MEAs), Toray carbon papers of thickness $0.37 \mathrm{~mm}$ with $15 \mathrm{wt} \%$ teflonization were used both for anodes and cathodes. For the diffusion layers, carbon slurry was prepared by dispersion of MC-PEDOT composites in 2-propanol with $15 \mathrm{wt} \%$ poly-tetrafluoroethylene under ultrasonication. The resultant slurry was applied onto the macroporous support with a loading of $1.5 \mathrm{mg} \mathrm{cm} \mathrm{cm}^{-2}$ on both the electrodes followed by sintering in a muffle furnace at $350^{\circ} \mathrm{C}$ for $30 \mathrm{~min}$. For the catalyst layer, $40 \mathrm{wt} \% \mathrm{Pt} / \mathrm{C}$ (Johnson Matthey) was 
dispersed in a mixture of 2-propanol and Nafion solution followed by ultrasonication for $20 \mathrm{~min}$ to form a homogeneous slurry. The slurry was then applied to the diffusion layers. The catalyst loading on both the anode and the cathode (active area $=25 \mathrm{~cm}^{2}$ ) were kept at $0.5 \mathrm{mg} \mathrm{cm}^{-2}$. A thin layer of Nafion ionomer was applied to catalyst surface of both the electrodes. MEAs were obtained by hot pressing the Nafion-1135 membranes sandwiched between cathodes and anodes under $60 \mathrm{~kg} \mathrm{~cm}^{-2}$ at $125^{\circ} \mathrm{C}$ for $3 \mathrm{~min}$. The MEAs were evaluated using a conventional $25 \mathrm{~cm}^{2}$ fuel cell fixture with parallel serpentine flow field machined on graphite plates (Schunk Kohlenstofftechnic). The cells were tested at $70^{\circ} \mathrm{C}$ with gaseous hydrogen and gaseous oxygen/air fed at atmospheric pressure at the anode and cathode sides, respectively. The flow rates for both hydrogen and oxygen/air gases were kept at $1.01 \mathrm{~min}^{-1}$ using mass flow controllers (Aalborg Instruments and Controls, US). Both the gaseous reactants were passed through humidifiers before feeding them to the cell.
After establishing the desired experimental conditions (dew point temperature $80^{\circ} \mathrm{C}$, gas temperature/gas supply temperature $85^{\circ} \mathrm{C}$, and dew point humidification temperature $85^{\circ} \mathrm{C}$ ) galvanostatic polarization data were obtained under steady state condition on the PEFCs using a fuel cell test station (model PEM-FCTS-158541) supplied by Arbin Instruments, US.

\section{Results and discussion}

\subsection{Characterizations of mesoporous carbon}

Synthesis of MC by surfactant molecular-aggregates comprises: (i) formation of supramolecular arrangement by polymerization of phloroglucinol and formaldehyde around the self-assembled surfactants (ii) cross-linking between surfactants and polymer resin, and (iii) carbonization of monolith to obtain the final product. Figures 1 and 2 show the $\mathrm{N}_{2}$
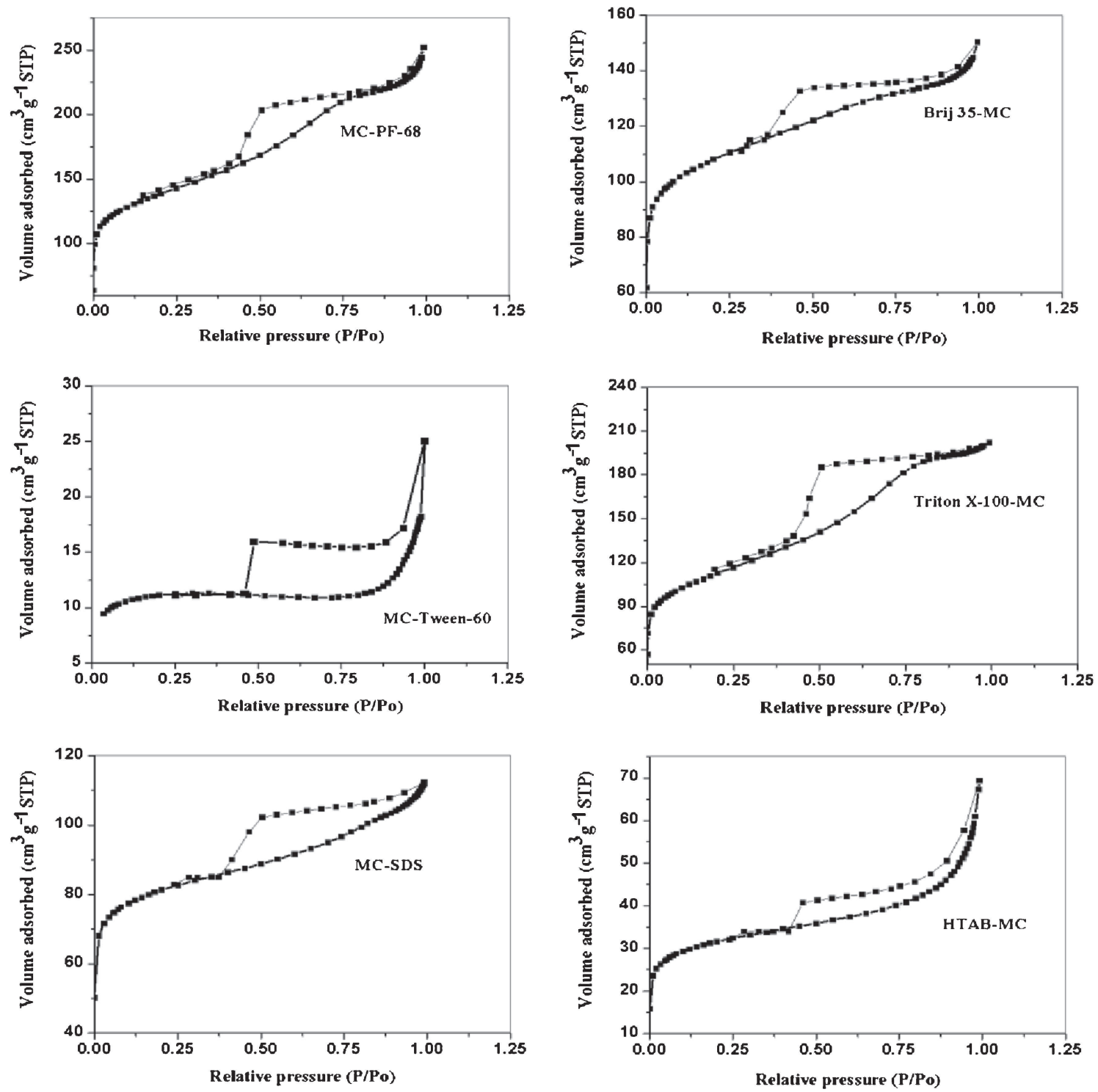

Figure 1. $\mathrm{N}_{2}$-sorption isotherms for mesoporous carbons derived from different structure-directing agents. 
adsorption and desorption isotherms and corresponding PSD curves of MCs prepared from different structure-directing agents.

The capillary evaporation took place at much lower relative pressures, which indicates that connections between the pores are much narrower than the pores themselves. ${ }^{61}$ All MCs exhibit pronounced hysteresis loop with sharp adsorption and desorption branches at medium and high relative pressure, indicating the mesoporous nature of the carbon. The values for BET surface area and the corresponding PSD analysis are summarized in table 1. In general, smaller the pore sizes of MCs, higher the surface area and larger the pore volume. All the MCs show higher surface area and pore volume than the Vulcan XC-72R carbon with an exception of MCs derived from HTAB and Tween-60 assisted synthesis.
It is interesting to note that the BET surface areas of PF68, Brij-35 and Triton X-100 assisted MCs are found to be 468, 402 and $383 \mathrm{~m}^{2} \mathrm{~g}^{-1}$, respectively. The corresponding PSD analysis derived from the adsorption branch of the isotherms indicates population of mesopores at 4.4, 3.9 and $2.2 \mathrm{~nm}$, respectively. For these MCs hydrogen bonding remains the key factor for preferential organization of carbon precursors in accordance with the spatial arrangement of neutral surfactant aggregates. Oligomers from phloroglucinol provide greater driving force for self-assemble interaction with hydrophilic tails of PF-68. High hydroxyl density that arises as three $-\mathrm{OH}$ groups form triple hydrogen-bonding per oligomer with the polyoxyethylene group of PF-68. Likewise, ether linkages, namely, oxyethylene group in Brij-35, Tween-60 and Triton X-100 lead to hydrogen bonds with
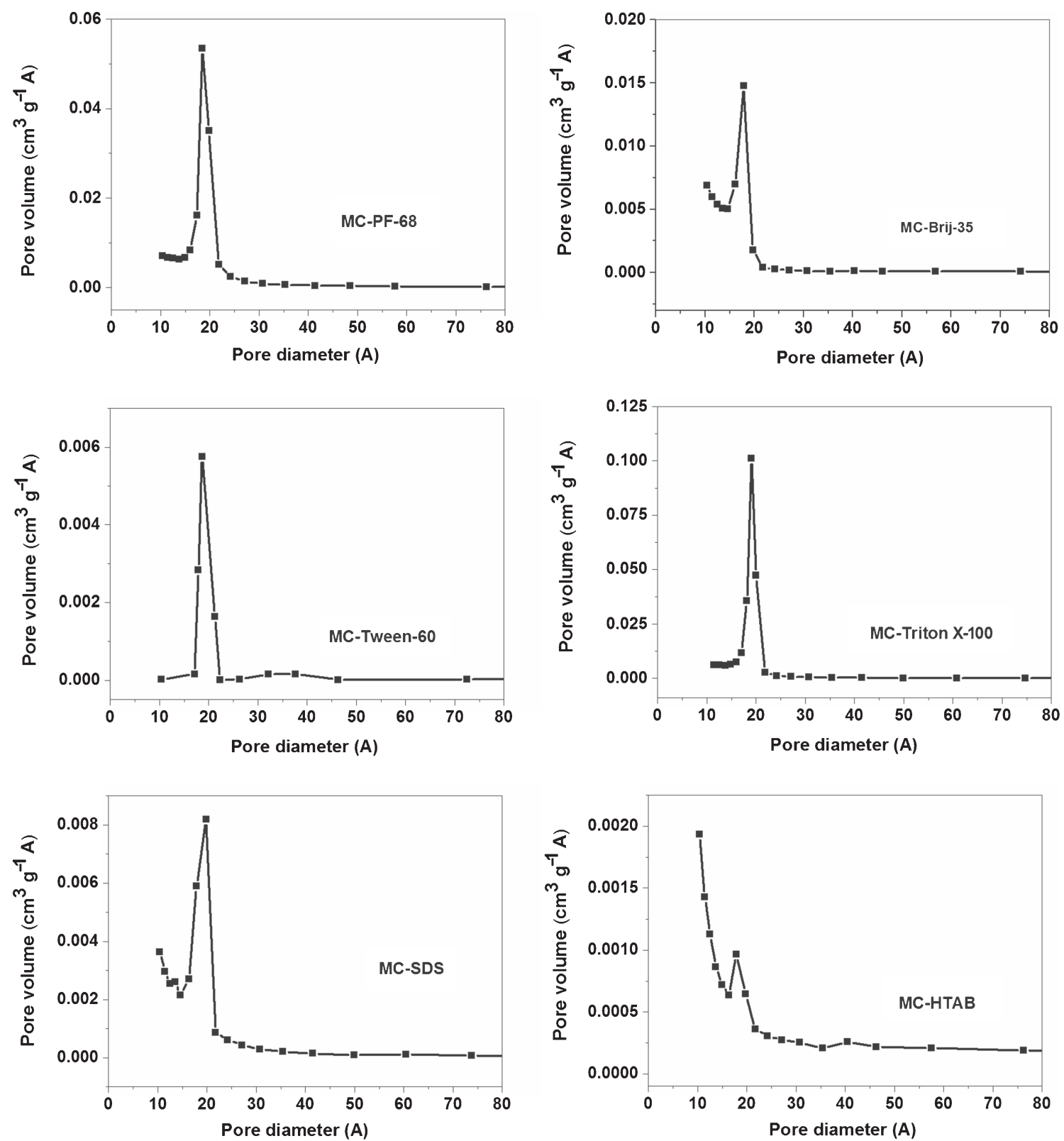

Figure 2. Pore size distribution data for mesoporous carbons derived from different structure-directing agents. 
the $-\mathrm{OH}$ groups of the phloroglucinol resulting in ordered spatial morphologies. However, MC derived from Tween60 has very low surface area of $42 \mathrm{~m}^{2} \mathrm{~g}^{-1}$ that may be due to the bulky structure of Tween-60, which does not allow proper alignment of carbon precursor with the hydrophilic tails of Tween-60 aggregates. Similarly, the BET surface area for MC prepared using ionic structure-directing agents such as SDS and HTAB are 307 and $106 \mathrm{~m}^{2} \mathrm{~g}^{-1}$, respectively. Morphologies of MCs can be changed based on the size and structure of the surfactant molecules. The intrinsic features in the synthesis of ordered porous materials are the self-assembly of molecules spatially organized by hydrogen bonding, hydrophobic/hydrophilic interactions, ion pairing, and/or dative interactions with the aggregates of cationic, anionic, and non-ionic surfactants, or block copolymers. Subsequently, the aggregates are removed by calcination followed by carbonization wherein the pores are formed with the structural replica of the type of surfactant used.

TEM study further corroborates these observations. Figure 3 shows the TEM images for MCs derived from different structure-directing agents. It is obvious that in all the cases no long-range pore ordering is observed due to the absence of any hard template during the synthesis of MCs. The use of mild structure-directing agents creates irregular structures based on the nature and properties of the surfactants used. Worm-like structure is clearly revealed for the MCs derived from PF-68 and Triton X-100 while soap bubble-like
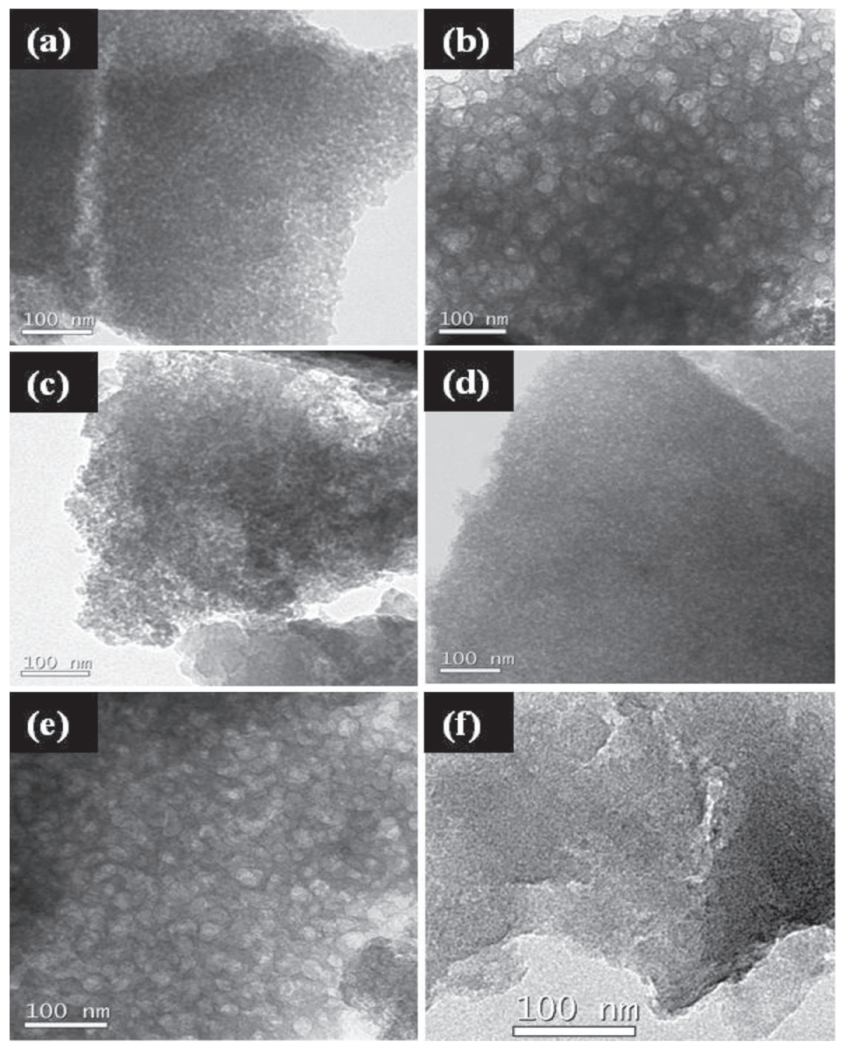

Figure 3. TEM pictures for mesoporous carbons derived from (a) PF-68, (b) Brij-35, (c) Tween-60, (d) Triton X-100, (e) SDS and (f) HTAB. Scale bar for all the pictures is $100 \mathrm{~nm}$. structures are observed for the MCs synthesised from SDS and Brij-35. Low surface area MCs, such as HTAB and Tween-60 exhibit irregular structures with wider pore structures.

Powder XRD patterns for the MCs synthesized from different structure-directing agents shown in figure 4 exhibit characteristic peaks at $23^{\circ}$ and $43^{\circ}$ confirming the carbonaceous nature of the samples with low crystallinity. The broad diffraction peaks at $23^{\circ}$ and $43^{\circ}$ are assigned to graphitic (002) and (101) planes, respectively. Peaks at these positions are more intense for MCs in relation to Vulcan XC$72 \mathrm{R}$, indicating comparatively higher degree of crystallinity for the former. ${ }^{42}$ The diffraction peak corresponding to (002) plane for MC-PF-68 suggests higher graphitic nature and is attributed to well-ordered structure resulted by the strong hydrogen bonding interaction between carbon precursors with self-assembled surfactants.

GDLs comprising different types of carbon are also evaluated for their air permeability prior to their use in the fuel cell. Figure 5 shows gas flow rate through the dry sample as a function of differential air-pressure acquired from the test samples of different GDLs. The flow rates are in volume of gas at standard pressure and standard temperature per unit time. Gas flow rate through the dry sample increases with increase in differential pressure as all the pores open up for gas flow. Gas flow rates which are the direct indication of the gas permeability through the samples, are measured using the equation

$$
F=k\left(A / 2 \mu l p_{\mathrm{s}}\right)\left(T_{\mathrm{s}} / T\right)\left(p_{\mathrm{i}}+p_{\mathrm{o}}\right)\left(p_{\mathrm{i}}-p_{\mathrm{o}}\right),
$$

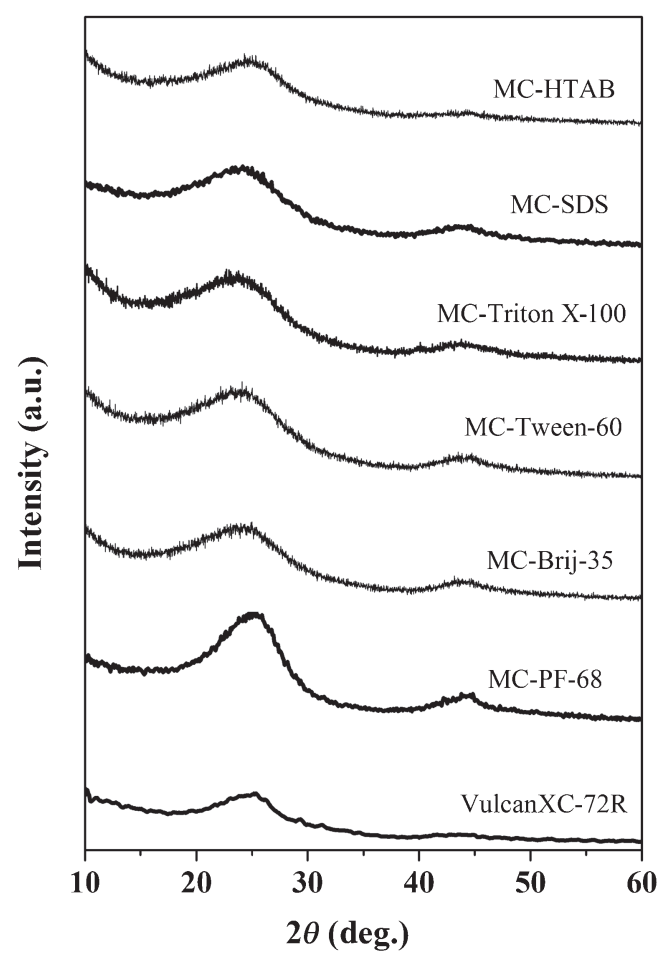

Figure 4. Powder XRD patterns for mesoporous carbons derived from different structure-directing agents. 


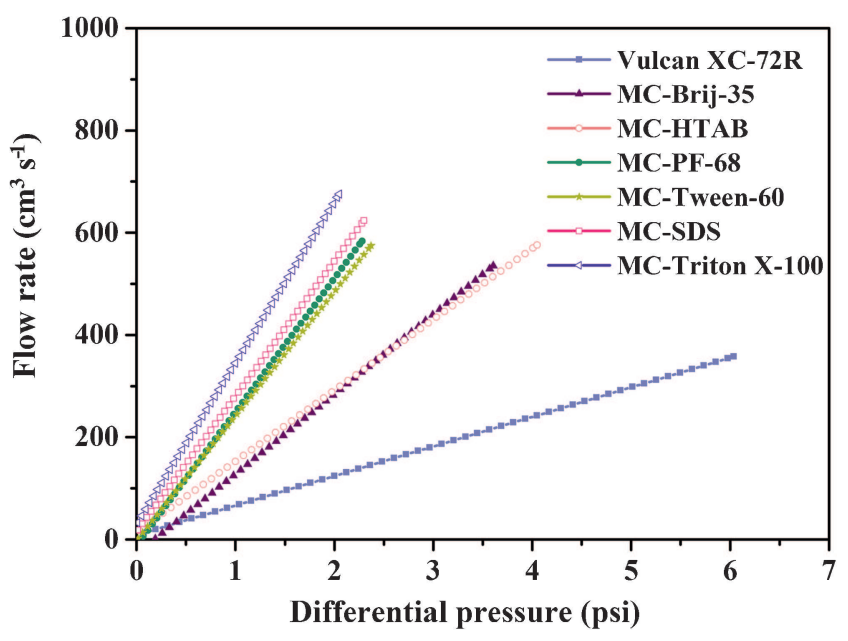

Figure 5. Plot of standard volume flow rate of air vs. differential pressure for GDLs coated with MCs derived from different structure-directing agents and GDL coated with Vulcan XC-72R.

where $\left(p_{\mathrm{i}}-p_{\mathrm{o}}\right)$ is the differential pressure, $l$ the thickness, $F$ the gas flow rate in volume per unit time at standard pressure $\left(p_{\mathrm{s}}\right)$, and standard temperature $\left(T_{\mathrm{s}}\right), A$ the cross-sectional area of the porous material, $k$ the specific permeability or simply permeability and $\mu$ the viscosity of the fluid. The data in figure 5 are used to compute air permeability using equation (1). The increase in slope indicates higher permeability values. The permeability value calculated for GDL coated with Vulcan XC-72R is 0.32 Darcy. The permeability for GDL coated with MCs (table 1) is higher in relation to the GDL coated with Vulcan XC-72R. This is a clear manifestation of higher air permeability for the electrodes comprising MCs and is primarily due to the presence of uniform and relatively larger pores present in the GDLs; a beneficial feature for fuel cells operating at higher current densities.

Figure $6 \mathrm{a}-\mathrm{d}$ shows SEM micrographs of GDL layers utilizing Vulcan XC-72R, and MCs synthesized from PF68, SDS and Triton X-100, respectively. The GDL coated with Vulcan XC-72R shows homogeneous carbon distribution with surface cracks. By contrast, GDL of MCs shows uniform carbon distribution and crack-free surfaces which facilitates the reactant gas to diffuse to the active catalyst sites.

\subsection{Fuel cell performances}

From the various physical characterization studies with a special focus on the gas permeability analysis for the MCs, MCs derived from PF-68, SDS and Triton X-100 are found to be superior in comparison to the porous carbon derived from other structure-directing agents. Accordingly, electrodes have been prepared from the above said selected MCs and constituted MEAs for evaluation in fuel cell mode. This has enabled us to identify the ideal pore structure, pore size distribution and their effective utilization in fuel cells. Fuel cell performance for the GDLs employing MC are compared
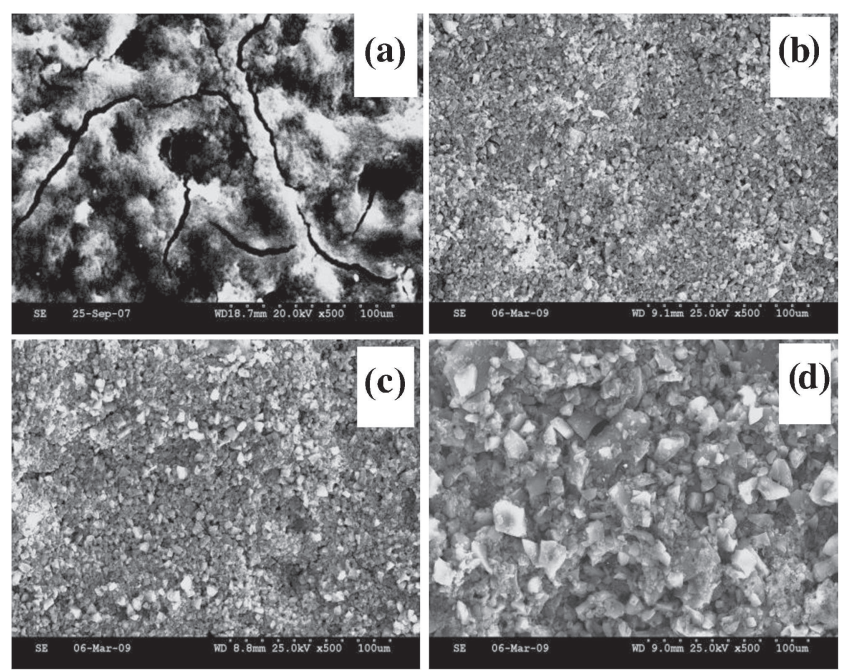

Figure 6. Typical SEM images for GDLs comprising (a) Vulcan XC-72R, (b) MC-PF-68, (c) MC-SDS and (d) MC-Triton X-100.

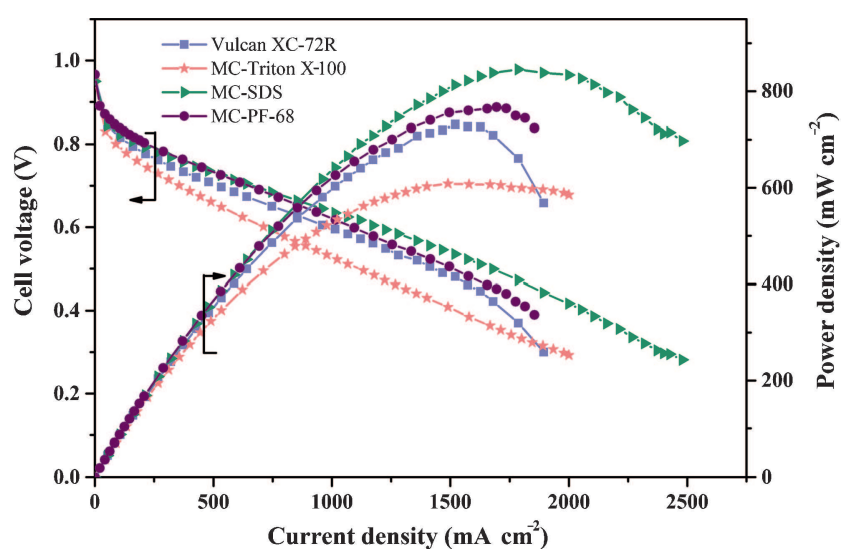

Figure 7. Galvanostatic polarization data at $70^{\circ} \mathrm{C}$ and atmospheric pressure for $\mathrm{H}_{2} / \mathrm{O}_{2}$ PEFCs comprising MEAs with GDLs coated with Vulcan XC-72R, MC-PF-68, MC-SDS and MC-Triton $\mathrm{X}-100$.

in relation to the electrodes with Vulcan $\mathrm{XC}-72 \mathrm{R}$ in the form of galvanostatic polarization data with $\mathrm{H}_{2} / \mathrm{O}_{2}$ and $\mathrm{H}_{2} /$ air feeds as shown in figures 7 and 8 , respectively.

It is seen that PEFCs with MCs as GDL deliver higher power densities in relation to the PEFC with GDL comprising Vulcan XC-72R. It is noteworthy that the peak power densities of 840 and $670 \mathrm{~mW} \mathrm{~cm}^{-2}$ are achieved for PEFC with GDL comprising MC-SDS with $\mathrm{H}_{2} / \mathrm{O}_{2}$ and $\mathrm{H}_{2}$ /air feeds, respectively. However, in case of GDL employing Vulcan $\mathrm{XC}-72 \mathrm{R}$ the respective power density values are 740 and $470 \mathrm{~mW} \mathrm{~cm}{ }^{-2}$. The larger pores available in the MCs help permeation of reactant gases to the active catalyst site. As a result, the mass-transfer region in the PEFCs is shifted towards higher load current-density and particularly so when air is used as an oxidant. Increase in power density for the PEFCs comprising MCs derived from SDS and PF-68 as GDL at high current density region is a clear manifestation 


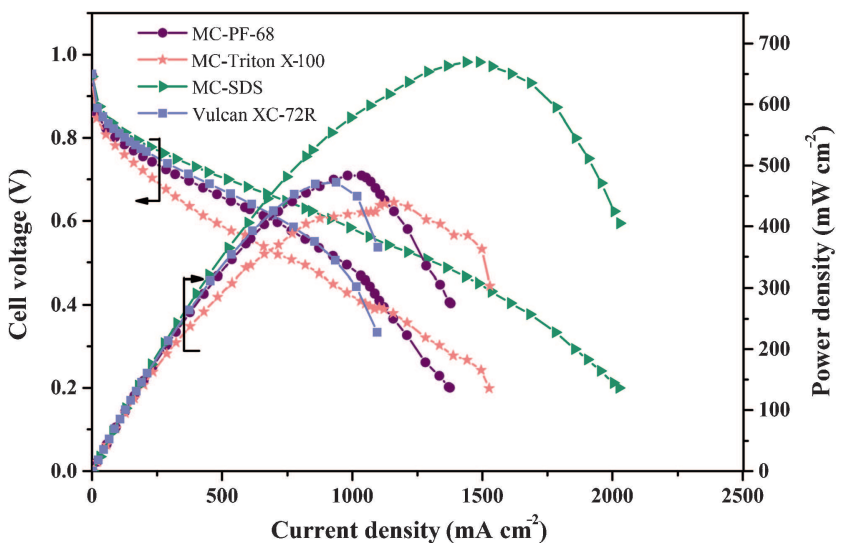

Figure 8. Galvanostatic polarization data at $70^{\circ} \mathrm{C}$ and atmospheric pressure for $\mathrm{H}_{2}$ /air PEFCs comprising MEAs with GDLs coated with Vulcan XC-72R, MC-PF-68, MC-SDS and MC-Triton $\mathrm{X}-100$.

of improved reactant-gas distribution and the subsequent removal of product water. The lower performance for the MC derived from Triton X-100 may be due to its relatively bigger particle sizes seen on the GDL surface (see figure 6d).

Generally choice of carbon materials for GDL depends on the required multi-functionality of its structure. Hence the factors such as surface area, pore size distribution, gas permeability and the surface morphology, strongly affect the performance of PEFCs. In the light of the foregoing, these parameters have been controlled by a rational choice of structure-directing agents during the synthesis of MCs and are investigated for their suitability in GDL in PEFCs. In the present study MCs of surface area between 300 and $500 \mathrm{~m}^{2} \mathrm{~g}^{-1}$, pore size in the range of $2-5 \mathrm{~nm}$, and the gas permeability in the range of 1-2 Darcy with suitable morphology look attractive for GDL in fuel cell electrodes.

\section{Conclusions}

The choice of porous carbon materials to evolve optimum GDL in a PEFC depends on the required multi-functionality of its structure and a trade-off between the properties such as pore volume and pore size distribution. MCs with varying porosities and morphologies are successfully synthesized by soft-template route comprising various thermally decomposable surfactants and utilized as GDL in electrodes for PEFCs. $\mathrm{N}_{2}$-sorption and TEM studies indicate that the MCs prepared from soft template route possess high surface area, large pore diameter and enhanced mesoporosity that are desirable features while designing effective gas diffusion layers for fuel cell electrodes. Reactant permeability with varying pore morphology are contrasted with water release behaviour of the electrodes and finally in PEFC performance. Hence the development of GDL with porous carbon of suitable surface area and pore size in the range of 4-6 nm ameliorates both the product water removal and the gas permeability to the active catalyst sites. Accordingly, fuel cell electrodes with
GDL containing MCs derived from SDS and PF-68 show higher air permeability and improved fuel cell performance.

\section{Acknowledgements}

Financial support from CSIR, New Delhi, under 12th five year plan D-NEED project (PSC 0109) is gratefully acknowledged. We thank Dr P Sridhar and Dr S Pitchumani for their helpful discussion. We thank Dr Vijayamohanan K Pillai, Director, CECRI, Karaikudi, for his encouragement and support.

\section{References}

1. Pharoah J G, Karan K and Sun W 2006 J. Power Sources 161 214

2. Williams M V, Begg E, Bonville L, Kunz H R and Fenton J M 2004 J. Electrochem. Soc. 151 A1173

3. Fischer A, Jindra J and Wendt H 1998 J. Appl. Electrochem. 28 277

4. Qi Z and Kaufman A 2002 J. Power Sources 10938

5. Lin G and Nguyen T V 2005 J. Electrochem. Soc. 152 A1942

6. Cindrella L, Kannan A M, Lin J F, Saminathan K, Ho Y, Lin C W and Wertz J 2009 J. Power Sources 194146

7. Pasaogullari U and Wang C Y 2004 J. Electrochem. Soc. 151 A399

8. Wilkinson D P, Voss H H and Prater K 1994 J. Power Sources 49117

9. Berg P, Promislow K, St Pierre J, Stumper J and Wetton B 2004 J. Electrochem. Soc. 151 A 341

10. Jordan L R, Shukla A K, Behrsing T, Avery N R, Muddle B C and Forsyth M 1999 J. Appl. Electrochem. 30641

11. Passalacqua E, Squadrito G, Lufrano F, Patti A and Giorgi L 2001 J. Appl. Electrochem. 31449

12. Neergat M and Shukla A K 2002 J. Power Sources 104289

13. Li W, Liang C, Zhou W, Qiu J, Zhou Z, Sun G and Xin Q 2003 J. Phys. Chem. B 1076292

14. Bessel C A, Laubernds K, Rodriguez N M and Baker R T K 2001 J. Phys. Chem. B 1051115

15. Wang H, Chowalla M, Sano N, Jia S and Amaratunga G A J 2004 Nanotechnology 15546

16. Wang J N, Zhao Y Z and Niu J J 2007 J. Mater. Chem. 172251

17. Kannan A M, Veedu V P, Munukutla L and Ghasemi-Nejhad M N 2007 Electrochem. Solid State Lett. 10 B47

18. Choi M and Ryoo R 2003 Nat. Mater. 2473

19. Davis M E 2002 Nature 417813

20. Liu D, Lei J H, Guo L P and Deng K J 2011 Carbon 492113

21. Joo S H, Choi S J, Oh I, Kwak J, Liu Z, Terasaki O and Ryoo R 2001 Nature 412169

22. Huang Y, Cai H, Yu T, Zhang F, Zhang F, Meng Y, Gu D, Wan Y, Sun X, Tu B and Zhao D 2007 Angew. Chem. Int. Ed. 461089

23. Ohkubo T, Miyawaki J, Kaneko K, Ryoo R and Seaton N A 2002 J. Phys. Chem. B 1066523 
24. Lee D, Lee J, Kim J, Kim J, Na H B, Kim B, Shin C H, Kwak J H, Dohnalkova A, Grate J W, Hyeon T and Kim H S 2005 Adv. Mater. 172828

25. Yoon S B, Kim J Y and Yu J S 2001 Chem. Commun. 559

26. Yoon S, Lee J, Hyeon T and Oh S M 2000 J. Electrochem. Soc. 1472507

27. Lee J, Yoon S, Oh S M, Shin C H and Hyeon T $2000 A d v$. Mater. 12359

28. Zhou H S, Zhu S M, Hibino M, Honma I and Ichihara M 2003 Adv. Mater. 152107

29. Li Q, Jiang R, Dou Y, Wu Z, Huang T, Feng D, Yang J, Yu A and Zhao D 2011 Carbon 491248

30. Su F B, Zeng J H, Bao X Y, Yu Y S, Lee J Y and Zhao X S 2005 Chem. Mater. 173960

31. Joo S H, Pak C, You D J, Lee S A, Lee H I, Kim J M, Chang H and Seung D 2006 Electrochim. Acta 521618

32. Wikander K, Ekstrom H, Palmqvist A E C, Lundblad A, Holmberg K and Lindbergh G 2006 Fuel Cells 621

33. Ryoo R, Joo S H, Kruk M and Jaroniec M 2001 Adv. Mater. 13 677

34. Lee J, Kim J and Hyeon T 2006 Adv. Mater. 182073

35. Bohme K, Einicke W D and Klepel O 2005 Carbon 43 1918

36. Hou P X, Yamazaki T and Orikasa H 2005 Carbon 432624

37. Hampsey J E, Hu Q Y, Wu Z W, Rice L, Pang J B and Lu Y F 2005 Carbon 432977

38. Lin Y R and Teng H 2003 Carbon 412865

39. Darmstadt H, Roy C, Kaliaguine S, Joo S H and Ryoo R 2003 Micropor. Mesopor. Mater. 60139

40. Solovyov L A, Shmakov A N, Zaikovskii V I, Joo S H and Ryoo R 2002 Carbon 402477

41. Kim T W, Park I S and Ryoo R 2003 Angew. Chem. 424375
42. Vinu A, Miyahara M, Sivamurugan V, Mori T and Ariga K 2005 J. Mater. Chem. 155122

43. Mann S and Ozin G A 1996 Nature 382313

44. Ma Z, Kyotani T and Tomita A 2000 Chem. Commun. 2365

45. Yoon S B, Kim J Y and Yu J S 2002 Chem. Commun. 1536

46. Ryoo R, Joo S H and Jun S 1999 J. Phys. Chem. B 1037743

47. Kim J Y, Yoon S B, Kooli F and Yu J S 2001 J. Mater. Chem. 112912

48. Han S and Hyeon T 1999 Chem. Commun. 1955

49. Wan Y, Yang H F and Zhao D Y 2006 Acc. Chem. Res. 39423

50. Liang C D, Hong K L, Guiochon G A, Mays J W and Dai S 2004 Angew. Chem. Int. Ed. 43578

51. Tanaka S, Nishiyama N, Egashira Y and Ueyama K 2005 Chem. Commun. 162125

52. Liang C D and Dai S 2006 J. Am. Chem. Soc. 1285316

53. Wang X, Liang C and Dai S 2008 Langmuir 247500

54. Zhang F Q, Meng Y, Gu D, Yan Y, Yu C Z, Tu B and Zhao D Y 2005 J. Am. Chem. Soc. 12713508

55. Meng Y, Gu D, Zhang F Q, Shi Y F, Yang H F, Li Z, Yu C Z, Tu B and Zhao D Y 2005 Angew. Chem. Int. Ed. 447053

56. Suryavanshi U B, Ijima T, Hayashi A, Hayashi Y and Tanemura M 2011 Chem. Commun. 4710758

57. Smarsly B and Antonietti M 2006 Eur. J. Inorg. Chem. 1111

58. Sahu A K, Nishanth K G, Selvarani G, Sridhar P, Pitchumani S and Shukla A K 2009 Carbon 47102

59. Tintula K K, Sahu A K, Shahid A, Pitchumani S, Sridhar P and Shukla A K 2010 J. Electrochem. Soc. 157 B1679

60. Tintula K K, Sahu A K, Shahid A, Pitchumani S, Sridhar P and Shukla A K 2011 J. Electrochem. Soc. 158 B622

61. Kang S K, Yu J S, Kruk M and Jaroniec M 2002 Chem. Commun. 1670 